\title{
Magnitude of Annual Soil Loss from a Hilly Cultivated Slope in Northern Vietnam and Evaluation of Factors Controlling Water Erosion
}

\author{
Kiyoshi Kurosawa, ${ }^{1}$ Nguyen Hai Do, ${ }^{2}$ Tat Canh Nguyen, $^{2}$ and Kazuhiko Egashira ${ }^{3}$ \\ ${ }^{1}$ Institute of Tropical Agriculture, Kyushu University, Fukuoka 812-8581, Japan \\ ${ }^{2}$ Faculty of Natural Resources and Environment, Hanoi University of Agriculture, Hanoi, Vietnam \\ ${ }^{3}$ Faculty of Agriculture, Kyushu University, Fukuoka 812-8581, Japan \\ Correspondence should be addressed to Kiyoshi Kurosawa, kurosawa@agr.kyushu-u.ac.jp
}

Received 26 December 2008; Revised 24 June 2009; Accepted 9 September 2009

Recommended by Yongchao Liang

A soil erosion experiment was conducted in northern Vietnam over three rainy seasons to clarify the magnitude of soil loss and factors controlling water erosion. The plot had a low (8\%) or medium (14.5\%) slope with land-cover of cassava or morning glory or being bare. Annual soil loss $\left(177\right.$ to $\left.2,361 \mathrm{~g} / \mathrm{m}^{2}\right)$ was a tolerable level in all low-slope plots but was not in some medium-slope plots. The effects of slope gradient and seasonal rainfall on the mean daily soil loss of the season were confirmed, but the effect of land-cover was not, owing to the small canopy cover ratio or leaf area index during the season. The very high annual soil loss $\left(>2,200 \mathrm{~g} / \mathrm{m}^{2}\right)$ observed in the first year of some medium-slope plots was the site-specific effect from initial land preparation. Since the site-specific effect was large, the preparation must be done carefully on the slope.

Copyright ( 2009 Kiyoshi Kurosawa et al. This is an open access article distributed under the Creative Commons Attribution License, which permits unrestricted use, distribution, and reproduction in any medium, provided the original work is properly cited.

\section{Introduction}

In northern mountainous region of Vietnam, cultivated area of upland crops, such as maize, soybean, and cassava, has been increased recently [1]. It signifies that the sloping land for crop cultivation is expanding in the region. This is perhaps attributable to the rural development policy ("Doi Moi" reform policy) enforced in 1986. However, the sediment yield from the Red River basin, that is, 6401,060 ton $/ \mathrm{km}^{2} /$ year [2], is ranked 15 th in the world [3]. Since the Red River basin includes the northern mountainous region, expansion of sloping cultivated land is presumed to raise soil loss by water erosion.

Shifting cultivation has been performed over a period of time by local people in northern mountainous region. However, the enforcement of the rural development policy prohibited shifting cultivation and promoted settlement of local people by the forestland allocation program started in 1992 [4]. Sloping land was allocated to local people for cultivation by this program, but soil fertility of the farmland declined quickly with cultivation, leading to abandonment of cultivated land. In Laos adjacent to Vietnam, shifting cultivation was also prohibited and local people were settled [5]. Due to population growth in the settled area in Laos, the cultivation area has been enlarged with intensive cropping. It caused aggravation of soil erosion, and input of labor, funds, and technology was obliged to recover from the erosion. The same situation is observed in the northern mountainous area of Vietnam.

Agriculture brings benefits to local people by production of crops. However, cropping on the sloping land consequently causes soil erosion, and if it occurs heavily, nutrientrich topsoil is carried away from the agricultural land, reducing soil fertility of the land. In addition, agrochemicals, chemical fertilizers, and sediments eroded away from the site pollute river and groundwater, bring about eutrophication of water, and reduce water storage capacity of reservoir in downstream [6]. Soil erosion should be controlled within the allowable level and its adverse effect on downstream should be avoided as much as possible. 
Once, we conducted a soil erosion experiment during a rainy season in northern Vietnam [7]. Here, the effect of rainfall on soil loss was identified, but that of soil composition was not observed and the effect of land-cover type was not clear. Occurrence of a large amount of soil loss in some plots was not explained by the common factors, which is mentioned later. Therefore, additional experiments were conducted during the rainy season in the following two years by using the same site. In response to the soil erosion experiments over a total of three rainy seasons, the present study was attempted to clarify the magnitude of annual soil loss and to evaluate the effects of land cover, slope gradient, seasonal rainfall, and site-specific conditions, on the mean daily soil loss of the season.

\section{Conceptual Framework Outlining the Approach Used}

For the factors influencing soil erosion, rainfall, soil, slope gradient, slope length, cover management, and support practices are the common factors, as introduced in the well-known soil loss prediction formula of RUSLE [8]. The amount of erosion can be explained usually by these factors, though it depends on the site which factor is stronger than the others.

However, soil surface characteristics (eroded parts, flow surface, depression, stone cover, crust, etc.), regarded as the site-specific factors, were pointed out as the significant factors of the erosion $[9,10]$. When the effect of the sitespecific factors is large, the effect of some of the common factors may be masked.

Under the soil erosion experiment at a site, rainfall condition and soil type cannot be controlled, but cover management can be done. Gradient and length of the slope can be changed by creating a terrace on the slope. For making sloping land agriculture sustainable, magnitude of soil erosion and its impact on downstream must be taken into consideration. If the magnitude of soil loss becomes large, effective erosion control measures should be taken. For this purpose, magnitude of the soil loss and the factors on the erosion must be evaluated properly at the site.

\section{Materials and Methods}

3.1. Location. The soil erosion experimental site was located in Vinh Yen Township of Vinh Phuc Province $\left(21^{\circ} 18^{\prime} 08^{\prime \prime}\right.$ $\mathrm{N}$ and $105^{\circ} 37^{\prime} 54^{\prime \prime} \mathrm{E}$ ), about $50 \mathrm{~km}$ northwest of central Hanoi City, as shown in Figure 1. The experimental area occupied nearly 1 hectare with an elevation around $25 \mathrm{~m}$ above sea level. The site was situated in a zone where rainfall is 1,200-1,600 and 200-400 $\mathrm{mm}$ during rainy (May through October) and dry (November through April) seasons, and where the annual mean temperature is $20-24^{\circ} \mathrm{C}$, and the monthly mean temperature is from $16-20^{\circ} \mathrm{C}$ in January to a little over $28^{\circ} \mathrm{C}$ in July [11].

The soil at the experimental site is classified as Acrisol according to the FAO/UNESCO soil classification system [12].

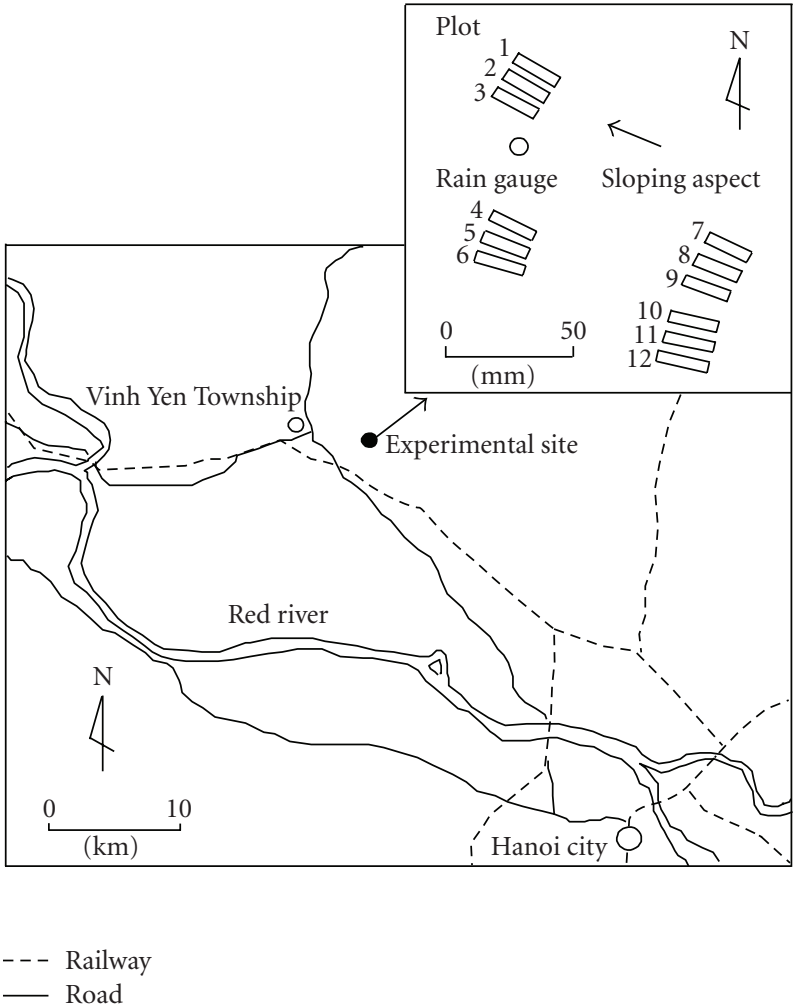

FIGURE 1: Location of the experimental site and the layout of the experimental plots.
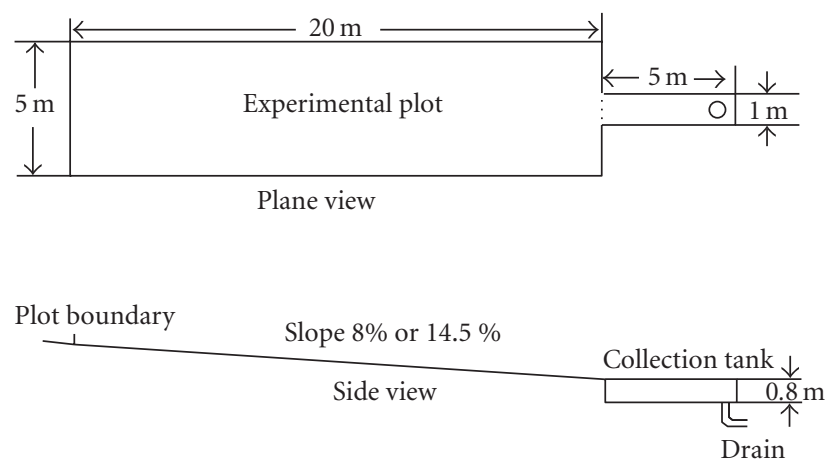

Figure 2: A scheme of the experimental setup.

3.2. Field Experimental Setup. Twelve experimental plots were set up on the hilly cultivated slope as shown in Figure 1. The schematic diagram of the experimental setup is illustrated in Figure 2. Each plot was $20 \mathrm{~m}$ long and $5 \mathrm{~m}$ wide with a gradient of $8.0 \%$ (referred to as the low slope) or $14.5 \%$ (referred to as the medium slope).

A $200 \mathrm{~mm}$ high earth bank was made as a plot boundary. The sloping aspect for the twelve plots ranged from $\mathrm{N} 62^{\circ} \mathrm{W}$ to $\mathrm{N} 78^{\circ} \mathrm{W}$. The experiment was carried out on all twelve plots in 2000, but on 6 plots of them in 2002 and 2003 (see Table 1). The experiment was conducted from May to September in 2000 and 2002 and from April to September in 2003, covering the major part of the rainy season. In the following, the experimental year of 2000 was referred to as 
the 1st year, and those of 2002 and 2003 were as the 2nd and 3rd years, respectively.

The twelve plots were divided into four groups of plots $1-3,4-6,7-9$, and $10-12$ which were designated as groups A, $\mathrm{B}, \mathrm{C}$, and $\mathrm{D}$, respectively, according to their locations.

The land-cover was arranged to the three types: (1) bare, (2) planted with morning glory, and (3) planted with cassava. Morning glory and cassava are commonly cultivated crops in the local area and grown only during the rainy season. Land preparation and crop planting were performed in March or early April using the following methods: (1) for the bare plot, topsoil was plowed to a depth of $50 \mathrm{~mm}$ and the surface was leveled off; (2) for the morning glory plot, morning glory grains were sowed with 72 to 80 grains per $\mathrm{m}^{2}$ after topsoil was plowed to a depth of $50 \mathrm{~mm}$; (3) for the cassava plot, 20 furrows were dug, each furrow being 150 to $200 \mathrm{~mm}$ deep and 350 to $400 \mathrm{~mm}$ wide, and 12 to 15 cassava stems were planted in a furrow followed by returning soil into each furrow.

Each plot used in the present experiment was renumbered from a previous numeric order [7] to a new one to include the morning glory plots.

3.3. Determination of Particle-Size Distribution. A topsoil sample $100 \mathrm{~cm}^{3}$ in volume was collected from the topsoil layer with a $50 \mathrm{~mm}$ depth at 10 separate spots in each plot at the 1st year. A composite sample was prepared by mixing them uniformly and provided to determine the average particle-size distribution for each plot. The content of gravel $(>2 \mathrm{~mm}$ ) was determined after sieving. Using the soil passed through a $2 \mathrm{~mm}$ sieve, the contents of sand $(2.0-0.02 \mathrm{~mm})$, silt $(0.02-0.002 \mathrm{~mm})$ and clay $(<0.002 \mathrm{~mm})$ were measured by the pipette method.

\subsection{Estimation of Canopy Cover Ratio and Leaf Area Index.} Canopy cover ratio, that is, the percent ratio of the crop canopy to the land in the area, was estimated for the 1st and 2nd years by measuring the horizontal canopy area per $1 \mathrm{~m}^{2}$ area of land. The measurement was performed mid-month at 5 separate locations in a plot, and their values were averaged to determine the value for each plot. The canopy cover ratio was measured every month until the end of the experiment.

Though canopy cover ratio was not measured for the $3 \mathrm{rd}$ year, LAI was measured as follows. An average leaf area per unit leaf weight was measured for several leaves, and all leaf weights were measured for an ordinary crop. The total leaf area of the crop was calculated from the average leaf area per unit leaf weight multiplied by the total leaf weight. This measurement was done for 5 separate crops in a plot, and the measured values were averaged. This average multiplied by the crop density (i.e., number of crops grown in a unit plot area) gave the LAI for the plot.

3.5. Monitoring of Rainfall and Soil Loss. One rain gauge (Omni Controls, Inc. Raingauge: RG600; and Datalogger: RG780) was installed at the experimental site (Figure 1), and rainfall in 10-minute intervals was monitored. This rainfall monitoring was only done for the 1st year and not done for the 2nd and 3rd years owing to a malfunction in the rain gauge. Instead, daily rainfall measured at the Vinh Yen Weather Station located about $3.5 \mathrm{~km}$ west of the experimental area was collected for the 2 nd and 3 rd years.

A concrete collection tank ( $1.0 \mathrm{~m}$ wide, $5.0 \mathrm{~m}$ long and $0.8 \mathrm{~m}$ deep) was constructed at the lower end of each plot to catch the soil eroded from the plot (Figure 2). The drain of each tank ( $100 \mathrm{~mm}$ in diameter) was covered with $1.5 \mathrm{~mm}$ wire mesh to allow water to drain while retaining all but the very fine particles inside the tank. Collection of soil from the tank was done once a day when any quantity of soil loss occurred. The daily soil loss was determined by weighing the collected soil after drying.

\section{Results}

4.1. Particle-Size Distribution of Topsoil. The particle-size distribution of topsoil for each plot is shown in Table 1. The contents (\%) of gravel, sand, silt, and clay ranged from 27.3 to $82.6,10.2$ to $55.1,2.3$ to 9.0 , and 5.0 to 21.2 , respectively. The particle-size distribution of ten out of twelve plots was quoted from the previous paper [7]. Though the particlesize distribution of plots 2 and 5 was newly presented in the present study, the contents of each fraction in the whole plot did not change with the addition of the new data. As a result, neither gravel nor sand occupied the largest portion of the topsoil. The combined content of those fractions was $70 \%$ or more in an individual plot. In contrast, silt occupied the smallest portion.

4.2. Canopy Cover Ratio and LAI. The monthly values of land-cover ratio, expressed either by canopy cover ratio or LAI, are presented in Table 2.

In the 1st year, the monthly canopy cover ratio of the cassava-planted plots increased from 8\%-9\% in May to 30\%$13 \%$ in September for the low slope, and from $13 \%-15 \%$ in June to $32 \%-34 \%$ in September for the medium slope. No substantial difference was found between the two slopes at any point throughout the experiment. The monthly canopy cover ratio of the morning-glory-planted plots in the 1st year increased from 7\%-8\% in May to 32\%-35\% in September for the low slope, indicating that there was no essential difference in the monthly canopy cover ratio between the two crops.

The monthly canopy cover ratio of the cassava-planted plots increased from 7\% in May to 53\% in September in the 2nd year, which was similar to the ratio in the 1st year during May and June, but larger than that recorded during July and September. The monthly canopy cover ratio of the morningglory-planted plots in the 2nd year was mostly below $10 \%$ throughout the season and was considerably lower than the ratio recorded in the 1st year. The lower ratio of the plot was due to the harvesting of morning glory leaves by local farmers for eating purpose. This intermittent harvesting is usually done in the local area. In the first year, however, the harvesting had not been done in any month.

In the 3rd year, LAI was measured for a cassava-planted plot and a morning-glory-planted plot only, because the canopy cover condition did not appear to be different 
TABLE 1: Slope, land-cover, and particle-size distribution of topsoil in the twelve plots.

\begin{tabular}{|c|c|c|c|c|c|c|c|c|c|}
\hline \multirow{2}{*}{ Group } & \multirow{2}{*}{ Plot No. } & \multirow{2}{*}{ Slope (\%) } & \multicolumn{3}{|c|}{ Land-cover } & \multicolumn{4}{|c|}{ Particle-size distribution (\%) } \\
\hline & & & 1st year & 2nd year & 3rd year & Gravel & Sand & Silt & Clay \\
\hline \multirow{3}{*}{ A } & 1 & 8.0 & Bare & NA & NA & 43.5 & 39.0 & 2.9 & 14.6 \\
\hline & 2 & 8.0 & MG & NA & NA & 31.1 & 45.2 & 5.9 & 17.8 \\
\hline & 3 & 8.0 & Cassava & NA & NA & 29.7 & 53.1 & 4.7 & 12.5 \\
\hline \multirow{3}{*}{ B } & 4 & 8.0 & Bare & NA & Bare & 44.6 & 43.4 & 2.9 & 9.2 \\
\hline & 5 & 8.0 & MG & NA & MG & 28.5 & 55.1 & 4.4 & 12.0 \\
\hline & 6 & 8.0 & Cassava & NA & Cassava & 27.3 & 47.9 & 6.0 & 18.7 \\
\hline \multirow{3}{*}{$\mathrm{C}$} & 7 & 14.5 & Bare & Bare & NA & 38.9 & 41.1 & 6.0 & 13.9 \\
\hline & 8 & 14.5 & Cassava & Cassava & NA & 48.5 & 29.9 & 6.6 & 15.0 \\
\hline & 9 & 14.5 & Cassava & MG & NA & 82.6 & 10.2 & 2.3 & 5.0 \\
\hline \multirow{3}{*}{$\mathrm{D}$} & 10 & 14.5 & Bare & Bare & Cassava & 29.8 & 40.0 & 9.0 & 21.2 \\
\hline & 11 & 14.5 & Cassava & Cassava & MG & 41.2 & 33.5 & 7.5 & 17.8 \\
\hline & 12 & 14.5 & Cassava & MG & Bare & 59.8 & 22.2 & 4.9 & 13.1 \\
\hline
\end{tabular}

MG: morning glory.

NA: not available because the experiment was not conducted or data was not complete.

TABLE 2: Monthly canopy cover ratio (\%) or LAI of the planted plots during the rainy season.

\begin{tabular}{lcccccccc}
\hline Year & Plot & Land-cover & Apr. & May & June & Jul. & Aug. & Sep. \\
\hline 1st & 3,6 & Cassava & NA & $8-9$ & $10-12$ & $13-16$ & $22-24$ & $30-31$ \\
& $8,9,11,12$ & Cassava & NA & NA & $13-15$ & $17-19$ & $24-25$ & $32-34$ \\
& 2,5 & MG & NA & $7-8$ & 12 & $21-22$ & $26-28$ \\
\hline 2nd & 8,10 & Cassava & NA & 7 & 12 & 24 & $32-35$ \\
& 9,11 & MG & NA & $3-5$ & $5-8$ & $4-9$ & $5-12$ & 6 \\
\hline \multirow{2}{*}{ 3rd } & 6 & Cassava & 0.05 & 0.25 & 1.00 & 2.25 & 3.95 & 5.20 \\
& 5 & MG & 1.32 & 2.42 & 1.98 & 2.28 & 1.68 & NA \\
\hline
\end{tabular}

MG: Morning glory.

Canopy cover ratio (\%) was measured in the 1st and 2nd year, while LAI was measured in the 3rd year.

NA: not available due to before planting in April and May and after harvesting in September.

between the plots for the same crop of the year. The LAI of the cassava-planted plot increased monthly from 0.05 in April to 5.2 in September. According to visual observation, the monthly growth of cassava canopy cover was almost the same between the 2 nd and 3rd years, although the land-cover ratio was expressed differently. The LAI of the morningglory-planted plot remained low with values less than 2.5 , which was also ascribed to the harvesting of leaves.

As a whole, the canopy cover ratio or LAI did not exceed $53 \%$ or 5.2 , respectively, showing that the crop canopy did not develop well to cover a large portion of land surface throughout the rainy season.

4.3. Rainfall and Soil Loss. Some rainfall statistics, that is, total rainfall and monthly and daily maximum rainfalls, during May and September in each year are listed in Table 3. Those three kinds of values ranged from 921 to 1,224, from 248 to 441 , and from 61 to $141 \mathrm{~mm}$, respectively. The total seasonal rainfall was the least in the 1st year, but the monthly and daily maximum rainfalls in the 1st year were larger than those in the 2nd year. The total, monthly, and daily maximum rainfalls were all the greatest in the 3rd year among the three years.
TABLE 3: Some rainfall statistics ( $\mathrm{mm}$ ) at or near the experimental site during May and September in each year.

\begin{tabular}{lccc}
\hline Rainfall statistics & 1st year $^{(1)}$ & 2nd year $^{(2)}$ & 3rd year $^{(2)}$ \\
\hline Total & 921 & 1102 & 1224 \\
Monthly maximum & 340 & 248 & 441 \\
Daily maximum & 83 & 61 & 141 \\
\hline
\end{tabular}

(1) : measured at the experimental site.

${ }^{(2)}$ : measured at the Vinh Yen Weather Station.

Table 4 shows the maximum, minimum, and mean daily soil loss recorded during each rainy season for each plot. The number of occurrence of soil loss during each rainy season is also given in Table 4. It varied from 22 to 31 with plots and years. Here, annual soil loss was nearly equal to the total of daily soil loss during a rainy season, because heavy rainfall that causes soil erosion occurs mostly in the rainy season of the year in the region. In total, 24 cases of annual soil loss were observed in the whole experiment.

As shown in Table 4, the maximum and mean daily soil loss varied widely from 15 to 395 and from 7 to $111 \mathrm{~g} / \mathrm{m}^{2}$, respectively, and the annual soil loss ranged from 151 to $2,442 \mathrm{~g} / \mathrm{m}^{2}$. The lowest values for each statistic were recorded 
TABLE 4: Daily and annual soil loss recorded during the rainy seasons of each year.

\begin{tabular}{|c|c|c|c|c|c|c|c|}
\hline \multirow{3}{*}{ Group } & \multirow{3}{*}{ Plot } & \multirow{3}{*}{ Year } & \multirow{3}{*}{$n$} & \multicolumn{4}{|c|}{ Soil loss $\left(\mathrm{g} / \mathrm{m}^{2}\right)$} \\
\hline & & & & & Daily & & \\
\hline & & & & Max & Min & Mean & Annual \\
\hline \multirow{3}{*}{ A } & 1 & $1 \mathrm{st}$ & 31 & 105 & 1 & 18 & 569 \\
\hline & 2 & $1 \mathrm{st}$ & 31 & 130 & 1.5 & 22 & 682 \\
\hline & 3 & $1 \mathrm{st}$ & 31 & 66 & 1.5 & 15 & 454 \\
\hline \multirow{6}{*}{ B } & 4 & 1 st & 31 & 67 & 2 & 15 & 475 \\
\hline & 4 & $3 \mathrm{rd}$ & 25 & 35 & 4 & 10 & 250 \\
\hline & 5 & $1 \mathrm{st}$ & 31 & 50 & 2 & 21 & 650 \\
\hline & 5 & $3 r d$ & 25 & 27 & 7 & 16 & 389 \\
\hline & 6 & 1 st & 31 & 36 & 1 & 8 & 256 \\
\hline & 6 & $3 \mathrm{rd}$ & 25 & 42 & 9 & 18 & 439 \\
\hline \multirow{6}{*}{$\mathrm{C}$} & 7 & 1 st & 22 & 80 & 3 & 21 & 467 \\
\hline & 7 & 2nd & 22 & 15 & 2 & 7 & 151 \\
\hline & 8 & $1 \mathrm{st}$ & 22 & 96 & 0.9 & 27 & 595 \\
\hline & 8 & $2 \mathrm{nd}$ & 22 & 20 & 3 & 8 & 176 \\
\hline & 9 & 1st & 22 & 180 & 4 & 47 & 1,025 \\
\hline & 9 & 2nd & 22 & 21 & 3 & 9 & 205 \\
\hline \multirow{9}{*}{$\mathrm{D}$} & 10 & $1 \mathrm{st}$ & 22 & 345 & 12 & 107 & 2,356 \\
\hline & 10 & $2 \mathrm{nd}$ & 22 & 20 & 4 & 9 & 209 \\
\hline & 10 & $3 \mathrm{rd}$ & 25 & 51 & 5 & 18 & 460 \\
\hline & 11 & $1 \mathrm{st}$ & 22 & 360 & 15 & 104 & 2,285 \\
\hline & 11 & 2nd & 22 & 28 & 3 & 9 & 195 \\
\hline & 11 & $3 \mathrm{rd}$ & 25 & 34 & 8 & 18 & 455 \\
\hline & 12 & $1 \mathrm{st}$ & 22 & 395 & 6 & 111 & 2,442 \\
\hline & 12 & $2 \mathrm{nd}$ & 22 & 20 & 4 & 9 & 187 \\
\hline & 12 & $3 \mathrm{rd}$ & 25 & 23 & 4 & 10 & 240 \\
\hline
\end{tabular}

$n$ : number of occurrence of soil loss.

at plot 7 in the 2 nd year while the highest values were recorded at plot 12 in the 1 st year.

The annual soil loss from the medium-slope plots varied widely with years. Namely, the average annual soil loss for plots 7 to 9 was $696 \mathrm{~g} / \mathrm{m}^{2}$ in the 1 st year but was as low as $177 \mathrm{~g} / \mathrm{m}^{2}$ in the $2 \mathrm{nd}$ year; that averaged for plots 10 to 12 was high in the 1 st year at $2,361 \mathrm{~g} / \mathrm{m}^{2}$ but was considerably low in the 2nd and 3rd years at only 197 and $385 \mathrm{~g} / \mathrm{m}^{2}$, respectively. Conversely, the annual soil loss from the low-slope plots did not vary so widely with years. The average annual soil losses from plots 1-3 in the 1st year and from plots 4-6 in the 1st and $3 r d$ years were $359-568 \mathrm{~g} / \mathrm{m}^{2}$, respectively.

\section{Discussion}

5.1. Magnitude of Annual Soil Loss. In the present study, the annual soil loss widely ranged from 150 to $2,440 \mathrm{~g} / \mathrm{m}^{2}$, and the average annual soil loss from the low and medium slopes was 460 and $760 \mathrm{~g} / \mathrm{m}^{2}$, respectively, as calculated from Table 4 . These averages for the low and medium slopes were less than or nearly equal to the annual soil loss of $700 \mathrm{~g} / \mathrm{m}^{2}$, which was previously observed on a gentle slope of the Red River basin [13].
As for tolerable levels of annual soil loss, a wide range spanning from 448 to $1,120 \mathrm{~g} / \mathrm{m}^{2}$ is standard in the United States [14]. However, it was lower than $1,120 \mathrm{~g} / \mathrm{m}^{2}$, especially for many intensively used but shallow soils found in the tropics and subtropics [15]. The annual soil loss from lowslope plots is reasonable to be regarded as a tolerable level, but the soil loss from the medium-slope plots 10,11, and 12 in the 1 st year, which was $2,285-2,442 \mathrm{~g} / \mathrm{m}^{2}$ (Table 4), is an intolerable level, because it far exceeded $1,120 \mathrm{~g} / \mathrm{m}^{2}$ of the maximum tolerable level above-mentioned.

5.2. Evaluation of Factors Controlling Water Erosion. Here, the factors controlling water erosion were evaluated by statistical analysis using the $t$-test or the Kruscal-Wallis test. The results are summarized in Table 5 .

5.2.1. Effect of Land-Cover on Soil Loss. Concerning the effect of land-cover on soil loss, whether there was or was not a significant difference in the mean daily soil loss of the season between the plots of each group in each year, was tested. The results are shown in the top section of Table 5.

As is shown in Table 5, a significant difference in the soil loss was recognized between plot pairs 4 to 6 (group B) in the 
TABLE 5: Significant differences in the mean daily soil loss between plots 1 to 12 , between groups A to D and between 1st to 3rd years analyzed by either the Kruskal-Wallis test or the $t$-test.

\begin{tabular}{|c|c|c|c|c|c|}
\hline \multirow{2}{*}{$\begin{array}{l}\text { Effect } \\
\text { examined }\end{array}$} & \multirow{2}{*}{ Group/year } & \multirow{2}{*}{$\begin{array}{l}\text { Plots/groups/years } \\
\text { examined for the } \\
\text { difference }\end{array}$} & \multirow{2}{*}{$n$} & \multicolumn{2}{|c|}{ Soil loss } \\
\hline & & & & $P$-value & $\begin{array}{l}\text { Plots/groups/years in } \\
\text { significant combinations }\end{array}$ \\
\hline \multirow[t]{8}{*}{$\begin{array}{l}\text { Land- } \\
\text { cover }\end{array}$} & $1 \mathrm{st}$ & $1,2,3$ & 31 & .117 & \\
\hline & 1st & $4,5,6$ & 31 & $.0001^{* *}$ & $4-6,5-6$ \\
\hline & $3 r d$ & $4,5,6$ & 25 & $<.0001^{* *}$ & $4-5,4-6$ \\
\hline & 1 st & $7,8,9$ & 22 & .093 & \\
\hline & $2 \mathrm{nd}$ & $7,8,9$ & 22 & .159 & \\
\hline & 1 st & $10,11,12$ & 22 & .855 & \\
\hline & $2 \mathrm{nd}$ & $10,11,12$ & 22 & .554 & \\
\hline & $3 \mathrm{rd}$ & $10,11,12$ & 25 & $<.0001^{* *}$ & $10-1211-12$ \\
\hline \multirow{3}{*}{$\begin{array}{l}\text { Slope } \\
\text { gradient }\end{array}$} & $1 \mathrm{st}$ & $A, B, C, D$ & $93^{(2)}, 66^{(3)}$ & $<.0001^{* *}$ & A-D, B-C, B-D \\
\hline & $3 \mathrm{rd}^{(1)}$ & $\mathrm{B}, \mathrm{D}$ & 75 & .221 & \\
\hline & $\mathrm{B}^{(1)}$ & 1st, 3rd & $93^{(4)}, 75^{(6)}$ & .387 & \\
\hline \multirow[t]{2}{*}{$\begin{array}{l}\text { Seasonal } \\
\text { rainfall }\end{array}$} & $\mathrm{C}^{(1)}$ & 1st, 2nd & 66 & $<.0001^{* *}$ & \\
\hline & $\mathrm{D}$ & 1st, 2 nd , 3rd & $66^{(4,5)}, 75^{(6)}$ & $<.0001^{* *}$ & $\begin{array}{l}\text { 1st-2nd, 1st-2nd, } \\
\text { 2nd-3rd }\end{array}$ \\
\hline
\end{tabular}

$N$ : number of observations for each group/year.

**: significance at $1 \%$ level.

${ }^{(1)}$ : analyzed by the $t$-test, and others were by the Kruscal-Wallis test.

(2) and ${ }^{(3)}$ : numbers for groups $\mathrm{A}$ and $\mathrm{B}$ and for groups $\mathrm{C}$ and $\mathrm{D}$, respectively.

$(4,5)$ and ${ }^{(6)}$ : numbers for 2000,2002 , and 2003 , respectively.

1st and 3rd years, and between plot pairs 10 to 12 (group D) in the 3rd year. The table indicates that the soil loss was less in the cassava-planted plot than in the bare plot, by comparison of plots 4 and 6 in the 1st year. However, the soil loss was considerably less in the bare plots than in the cassava- or morning-glory-planted plots in all the significant pairs for the 3rd year. If there is a positive relationship between landcover ratio and the soil loss, it should be observed less in the planted plot than in the bare plot, because canopy cover usually diminishes the soil loss by covering land surface. No significant difference was recognized between the bare and planted plots for plots 1 to 3 (group A) in the 1st year, and plots 7 to 9 (group C) and 10 to 12 in both the 1st and 2nd years. Therefore, the effect of canopy cover on the soil loss is considered unclear. This is probably due to the fact that the crop canopy did not develop well to cover the majority of the land surface during the season.

5.2.2. Effect of Slope Gradient on Soil Loss. The results of statistical analysis, which examined whether there was a significant difference in the mean daily soil loss according to the slope gradient, are shown in the middle section of Table 5. All occurrences of daily soil loss in groups A to D were used in the analysis.

The significant difference in the mean daily soil loss was observed between low and medium slopes of between groups $\mathrm{A}$ and $\mathrm{D}, \mathrm{B}$ and $\mathrm{C}$, and $\mathrm{B}$ and $\mathrm{D}$, respectively in the 1st year. This result exemplifies a positive relationship between slope gradient and daily soil loss. However, such a relationship was not indicated, because the combination of groups $\mathrm{A}$ and $\mathrm{C}$ in the 1st year and that of groups B and D in the 3rd year were not recognized as significantly different in Table 5 .

The above result, which showed that there was no consistent effect of slope gradient on the mean daily soil loss over the years, was unexpected, because the effect of slope gradient on soil loss should have been recognized, based on the physical principle of the erosion [16]. As a possible reason for why the effect of slope gradient was not apparent here, it was considered that both low and medium slopes were in the same category of gentle slope.

5.2.3. Effect of Seasonal Rainfall on Soil Loss. A statistical analysis on whether there was a significant difference in the mean daily soil loss between years is shown in the bottom section of Table 5 . Here, a significant difference was recognized between the 1st and 2nd years in group $\mathrm{C}$ and between each pair of each year in group $\mathrm{D}$ (medium slope). However, no significant difference was recognized between the 1 st and 3rd years in group B (low slope).

Regarding the mean daily soil loss from the mediumslope plots (Table 4), loss was significantly higher in the 1st year than in the 2nd year in group C. For group D, loss was significantly higher in the 1st year than in both the 2nd and 3rd years. In addition, the soil loss in the 3rd year was significantly higher than that in the 2 nd year in group D. As a result, the soil loss was the highest in the 1st year among the 
three years in both groups $\mathrm{C}$ and $\mathrm{D}$ and the second highest in the 3rd year in group D.

As a reason for the higher soil loss in the 3rd year than in the 2nd year in group D, the effect of seasonal rainfall was conceivable, because all rainfall statistics during the rainy season were larger in the 3rd year than in the 2nd year (Table 3). However, the largest soil loss from group D in the 1st year was not explainable through the magnitude of seasonal rainfall, because the rainfall statistics for the 1st year were not the highest among the three years. In addition, there was no significant difference in the soil loss between the 1st and 3rd years in group B. Therefore, it was suggested that the effect of seasonal rainfall on the mean daily soil loss was limited depending on the years.

5.2.4. Site-Specific Effect on Soil Loss. All the factors examined above did not explain well the differences in the mean daily soil loss between years or plots. Thus, other factors must be considered.

In the previous study [7], a possibility of the influence of site-specific condition of the plots was considered. As understood from Table 4, the annual soil loss from group D (more than $2,200 \mathrm{~g} / \mathrm{m}^{2}$ ) was much higher than that from groups A to C (no more than $1,100 \mathrm{~g} / \mathrm{m}^{2}$ ) for the 1st year. However, such large difference in the soil loss between group $\mathrm{D}$ and the other three groups was not confirmed in the 2nd and 3rd years (the middle section of Table 5). Therefore, the site-specific effect, even if it exists, was not consistent across the years.

The annual soil loss occurred in group $\mathrm{D}$ of the 1st year was very high compared to others. Crop cultivation had been practiced at the experimental area until 1999. The experimental plot was created in early 2000 of the 1st year, and the plots were perhaps in the situation of being new farmland in the 1st year. As a result, it is considered that creation of plots might have provided a favorable condition for group D to yield such excessive soil loss in the 1st year.

Trace of rill was observed visibly on the slope surface of group D in the 1st year but it was not confirmed in 2nd or 3rd year on any slope. Therefore, the rill erosion occurred on that slope in connection with the initial land preparation of the experimental plot is the most probable cause of the very high soil loss in group D of the 1st year and which can also be regarded as a site-specific effect.

\section{Conclusions}

The soil erosion experiment was conducted on the sloping land in the Red River basin of northern Vietnam by using plots over three rainy seasons. Amount of rainfall during the rainy season was $921-1224 \mathrm{~mm}$. Canopy cover ratio or leaf area index of the crop of cassava or morning glory was $53 \%$ or $5.2 \%$ at maximum during the season, though it increased with time. Seasonal (equivalent to annual) soil loss from the plots of low and medium slopes, that is, $8 \%$ or $14.5 \%$, respectively, in gradient, was $359-568 \mathrm{~g} / \mathrm{m}^{2}$ and $177-$ $2,361 \mathrm{~g} / \mathrm{m}^{2}$, respectively.
The soil loss amount was considered as a tolerable level $\left(<1,120 \mathrm{~g} / \mathrm{m}^{2}\right)$ in low-slope plots but far exceeded the tolerable level in some medium-slope plots. The effects of slope gradient and the amount of rainfall on the mean daily soil loss during the rainy season were confirmed but not for all cases examined. No marked effect of land-cover on the mean daily soil loss was observed. It was probably because crop canopy did not grow to cover the majority of the land surface during the season.

The very high annual soil loss of more than $2,200 \mathrm{~g} / \mathrm{m}^{2}$, recorded in some medium-slope plots only in the first year of the experiment, was regarded as a site-specific effect in connection with the initial land preparation. Since the sitespecific effect is large, the initial land preparation for crop cultivation must be done carefully on the slope not to disturb the topsoil deeply.

\section{References}

[1] General Statistics Office, Statistical Yearbook of Vietnam 2007, Statistical Publishing House, Hanoi, Vietnam, 2008.

[2] T. P. Q. Le, J. Garnier, B. Gilles, T. Sylvain, and C. Van Minh, "The changing flow regime and sediment load of the Red River, Viet Nam," Journal of Hydrology, vol. 334, no. 1-2, pp. 199-214, 2007.

[3] J. D. Milliman and J. P. M. Syvitski, "Geomorphic/tectonic control of sediment discharge to the ocean: the importance of small mountainous rivers," Journal of Geology, vol. 100, no. 5, pp. 525-544, 1992.

[4] F. Clement and J. M. Amezaga, "Linking reforestation policies with land use change in northern Vietnam: why local factors matter," Geoforum, vol. 39, no. 1, pp. 265-277, 2008.

[5] G. Lestrelin and M. Giordano, "Upland development policy, livelihood change and land degradation: interactions from a Laotian village," Land Degradation \& Development, vol. 18, no. 1, pp. 55-76, 2007.

[6] S. Khan and M. A. Hanjra, "Sustainable land and water management policies and practices: a pathway to environmental sustainability in large irrigation systems," Land Degradation \& Development, vol. 19, no. 5, pp. 469-487, 2008.

[7] K. Kurosawa, M. D. Nguyen, C. T. Nguyen, H. Q. Trinh, and H. T. D. Do, "Factors affecting soil erosion on cassava cultivated hill slope in northern Vietnam," Japanese Journal of Tropical Agriculture, vol. 48, no. 1, pp. 17-24, 2004.

[8] United States Department of Agriculture-Agriculture Research Service, "Revised universal soil loss equation 1.06-Description of RUSLE1.06c," 2007, http://www.ars .usda.gov/Research/docs.htm?docid=5975.

[9] E. Bergsma, "Erosion intensity evaluated from microtopographic soil erosion features, its correlation with conservation practice, presence of fertilizer, and erosion development between alley cropping hedges : the case study of Doi Thung and Nan, Northern Thailand," in Sustaining the Global Farm, D. E. Stott, R. H. Mohtar, and G. C. Steinhardt, Eds., pp. 666675, West Lafayette, Ind, USA, 2001.

[10] A.-V. Auzet, P. van Dijk, and M. J. Kirkby, "Surface characterisation for soil erosion forecasting," Catena, vol. 62, no. 2-3, pp. 78-79, 2005.

[11] T. C. Vu, T. D. Nguyen, and D. T. Ngo, Atlat Dia Li Vietnam, Education Publishing House, Hanoi, Vietnam, 2006.

[12] VSSS-NIAP (Vietnam Soil Science Society-National Institute of Agriculture Planning and Projection), Ed., Soil Map of 
Vietnam (Scale 1:1,000,000), VSSS-NIAP, Hanoi, Vietnam, 1996.

[13] D. S. Do and B. N. Nguyen, Assessment of Potential Productivity of Forest Land in Vietnam, Statistics Publishing House, Hanoi, Vietnam, 2001.

[14] F. R. Troeh, J. A. Hobbs, and R. L. Donahue, Soil and Water Conservation: Productivity and Environmental Protection, Prentice Hall, Upper Saddle River, NJ, USA, 1999.

[15] R. Lal, "Agronomic consequences of soil erosion," in Soil Erosion at Multiple Scales, F. W. T. Penning de Vries, F. Agus, and J. Kerr, Eds., pp. 149-160, CABI, Wallingford, UK, 1998.

[16] T. J. Toy, G. R. Foster, and K. G. Renard, Soil Erosion: Processes, Prediction, Measurement, and Control, John Wiley \& Sons, New York, NY, USA, 2002. 

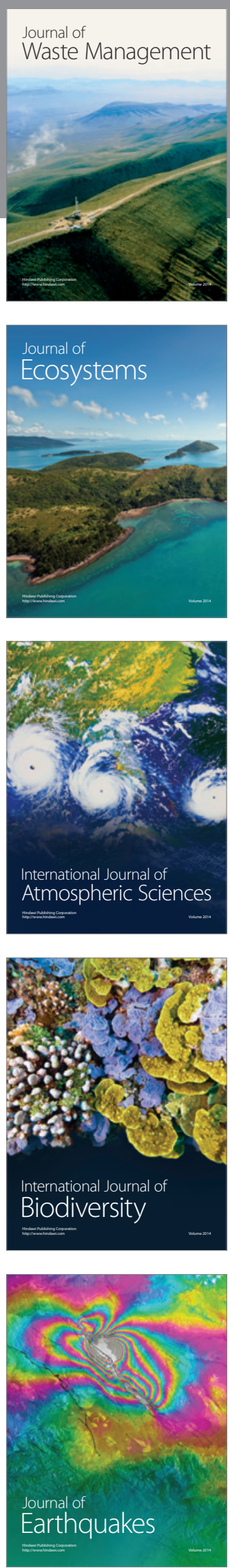
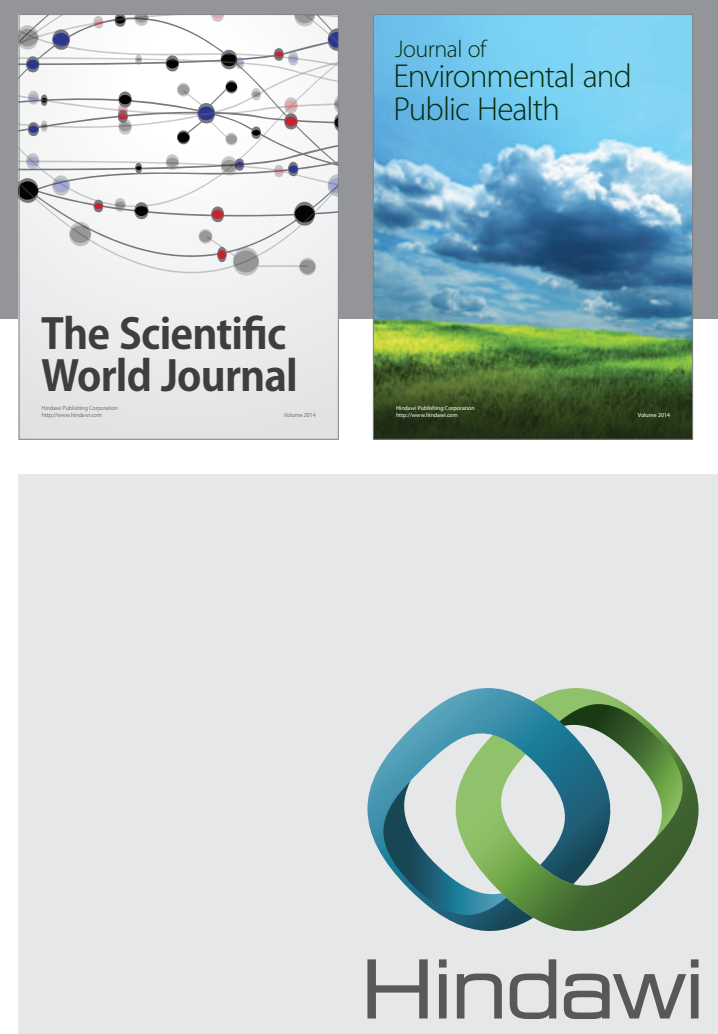

Submit your manuscripts at

http://www.hindawi.com
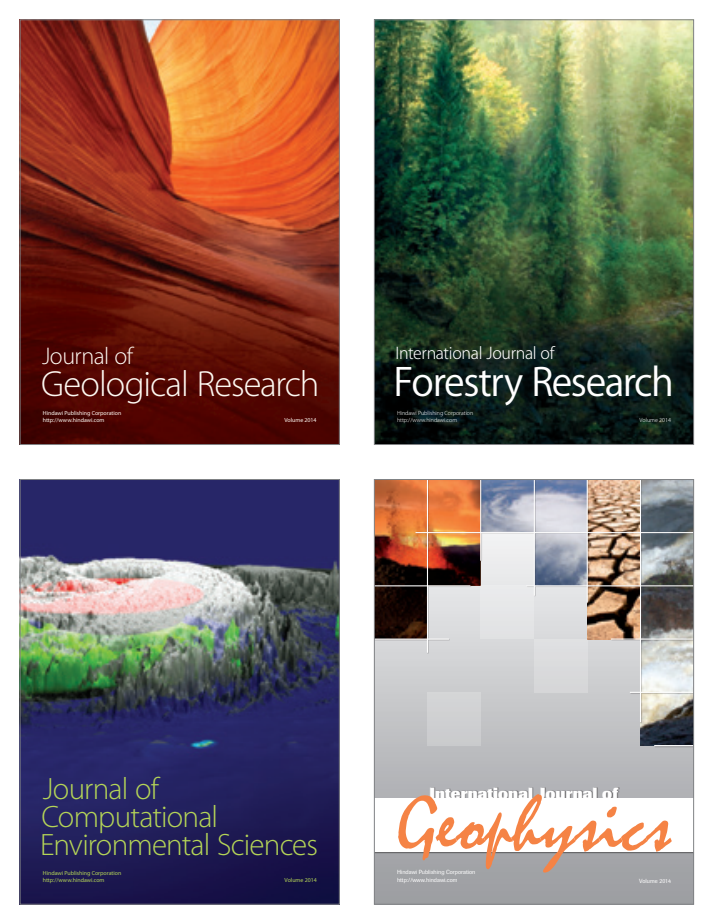
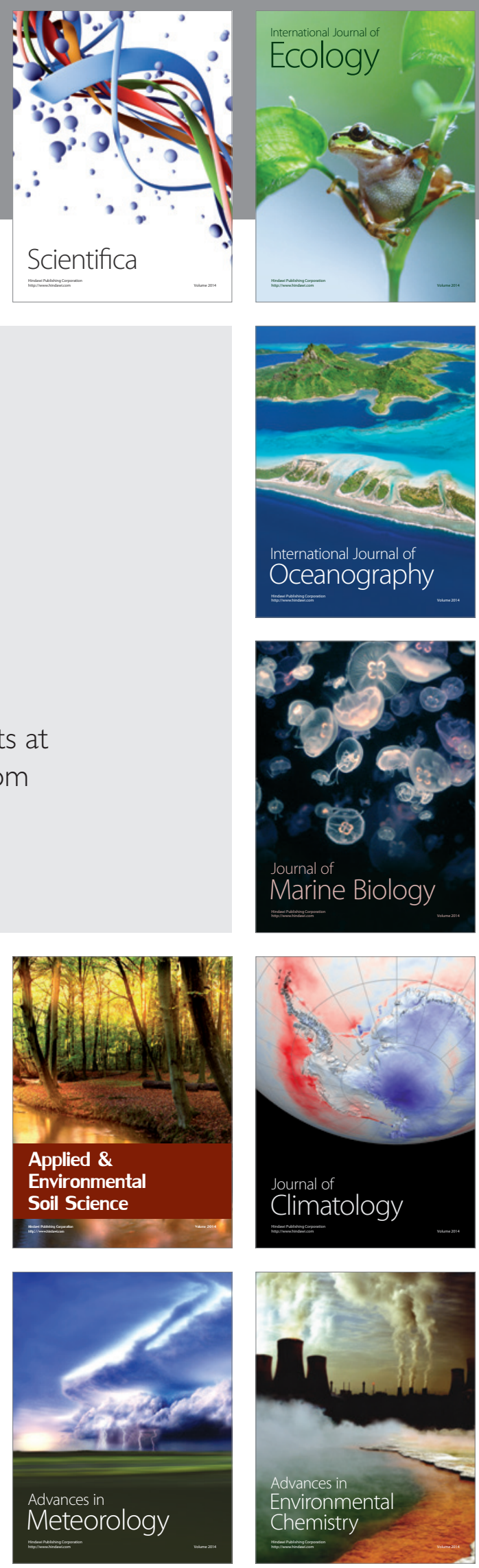